\title{
Inflammatory status in older women with and without metabolic syndrome: is there a correlation with risk factors?
}

This article was published in the following Dove Press journal:

Clinical Interventions in Aging

26 March 2013

Number of times this article has been viewed

\author{
Alessandro de Oliveira \\ Silva ${ }^{1,2}$ \\ Ramires Alsamir Tibana' \\ Margo Gomes Oliveira \\ Karnikowski ${ }^{3}$ \\ Silvana Schwerz Funghetto ${ }^{3}$ \\ Jonato Prestes' \\ 'Graduation Program in Physical \\ Education and Health, Catholic \\ University of Brasilia, ${ }^{2}$ Physical \\ Education Department, Universitary \\ Center of Brasilia, ${ }^{3}$ Ceilandia Faculty, \\ University of Brasilia, Brasilia, Brazil
}

Correspondence: Alessandro de Oliveira Silva

Graduation Program on Physical

Education, Catholic University of Brasilia, QS 07 Lote 0I - Bloco G, 71966-700

Brasilia, Brazil

Tel +2I 556 I 33569350

Fax $+2 \mid 556133569350$

Email silva.alessandro.oliveira@gmail.com
Purpose: To compare the inflammatory status in older women with and without metabolic syndrome (MetS) and to correlate inflammatory parameters, anthropometric measures, metabolic profile, and blood pressure with MetS Z-score.

Methods: This cohort transversal study included 129 older women assigned into two groups: with MetS ( $=48 ; 66.4 \pm 4.4$ years; $\left.68.1 \pm 8.3 \mathrm{~kg} ; 1.51 \pm 0.06 \mathrm{~m} ; 29.8 \pm 3.9 \mathrm{~kg} / \mathrm{m}^{2}\right)$ and without MetS ( $\mathrm{n}=81 ; 68.0 \pm 5.8$ years; $61.0 \pm 9.4 \mathrm{~kg} ; 1.53 \pm 0.06 \mathrm{~m} ; 26.0 \pm 3.9 \mathrm{~kg} / \mathrm{m}^{2}$ ). Body composition was evaluated by dual-energy X-ray absorptiometry (General Electric-GE model 8548 BX1L, year 2005, Lunar DPX type, software Encore 2005; Rommelsdorf, Germany) and cytokines by enzyme-linked immunosorbent assay.

Results: There was no difference between the groups regarding age, height, fat mass, glycosylated hemoglobin, total cholesterol, and low-density lipoprotein cholesterol. However, older women with MetS presented higher body mass, body mass index, waist and hip circumference, waist-hip and waist-height ratio, systolic, diastolic, and mean blood pressure, glucose, insulin, homeostasis model assessment of insulin resistance, MetS Z-score, tumor necrosis factor- $\alpha$, interferon- $\gamma$, and lower lean body mass values compared to women without MetS. Moreover, there were correlations between MetS Z-score and body mass $(r=0.20)$, waist circumference $(r=0.26)$, waist-hip $(r=0.32)$ and waist-height ratio $(r=0.24)$, blood glucose $(r=0.24)$, insulin $(r=0.24)$, homeostasis model assessment of insulin resistance $(r=0.32)$, triglycerides $(r=0.39)$, tumor necrosis factor- $\alpha(r=0.28)$, interferon- $\gamma(r=0.22)$, and inverse correlation with high-density lipoprotein cholesterol $(\mathrm{r}=-0.32)$. MetS Z-score was positively associated with systolic $(\mathrm{r}=0.92)$, diastolic $(\mathrm{r}=0.94)$, and mean blood pressure $(\mathrm{r}=0.98)$.

Conclusion: Older women with MetS have higher cytokine levels, anthropometric measures, metabolic profile, and blood pressure. Inflammatory cytokines may help to improve the understanding of the progression status of MetS in older persons.

Keywords: metabolic syndrome, cytokines, aging

\section{Introduction}

Metabolic syndrome (MetS) is characterized by a group of risk factors (eg, abdominal obesity, atherogenic dyslipidemia, elevated blood pressure, insulin resistance) that increases the risk of all-cause and cardiovascular death. ${ }^{1,2}$ The disorder is associated with insulin resistance, with excessive flux of fatty acids implicated and the proinflammatory state as a probable contributor. Additionally, the increased risk for type II diabetes and cardiovascular disease demands therapeutic attention for those at high risk. ${ }^{1}$ The Third National Health and Nutrition Examination Survey (1988-1994) reported that more than $20 \%$ of the adult population in the US suffered from MetS. ${ }^{3,4}$ A recent National Health and Nutrition Examination Survey (2003-2006) statement reported that the 
prevalence rates of MetS were $35.1 \%$ in men and $32.6 \%$ in women. ${ }^{5}$ In Brazil, Dutra et al reported that the prevalence rates of MetS was 32\% with no gender difference. ${ }^{6}$

Obesity, insulin resistance, and type II diabetes have been characterized as chronic "inflammatory" states that are associated with abnormal concentrations of cytokines, acute phase reactants, and other inflammatory signaling markers. ${ }^{7-10}$ Moreover, MetS is believed to be associated with chronic inflammatory response, which is characterized by increased cytokine production and the activation of inflammatory signaling pathways. ${ }^{9}$ Additionally, evidence for this issue is provided by the observation of an association between high levels of C-reactive protein (CRP), a sensitive marker of subclinical inflammation with insulin resistance or components of MetS. ${ }^{9,11}$ Of note, a biological dysfunction in postmenopausal older women is the "senile inflammation," with a strong temporal relationship between aging, inflammation, and menopause. ${ }^{12}$ However, the relationship between inflammatory cytokines, MetS, and aging has yet to be determined.

Although previous studies have targeted the association of MetS with one or a few inflammatory biomarkers, to the best of the authors' knowledge no study was designed to analyze the relationship between inflammatory biomarkers, anthropometric measures, metabolic profile, and blood pressure with MetS Z-score in Brazilian older women. Awareness regarding the elevation of cytokines and their association with MetS in older persons should be an issue in gerontology. Therefore, the purpose of this study was to compare the inflammatory status of older women with and without MetS and to correlate inflammatory parameters, anthropometric measures, metabolic profile, and blood pressure with MetS Z-score. The initial hypothesis was that older women with MetS would present higher blood cytokines and a correlation of these parameters with MetS Z-score.

\section{Methods}

This was a cohort transversal study with elderly women living in a local community. One-hundred and twenty-nine sedentary elderly women were selected by convenience and were not specifically representative of the Brazilian population. Participants were recruited on a voluntary basis from the local community from posters and lectures about the study. They were considered sedentary by accruing less than 2 hours per week of physical activity during the last year. They completed an anamnesis form and physical activity questionnaire and were subjected to anthropometric measures. A total of 250 older women gave their informed consent. Later, 121 subjects were excluded from the analysis due to any malignancy, immunosuppressive therapy, known inflammatory disease (eg, arthritis, inflammatory bowel disease, psoriasis), acute infection or invasive procedures (eg, surgery, catheterization) during the last 6 months as evaluated in the anamnesis form. Following these exclusions, the study group comprised 129 older women $(67.4 \pm 5.4$ years; $\left.63.6 \pm 9.6 \mathrm{~kg} ; 1.52 \pm 0.06 \mathrm{~m} ; 29.8 \pm 3.9 \mathrm{~kg} / \mathrm{m}^{2}\right)$ assigned into two groups: with MetS $(n=48 ; 66.4 \pm 4.4$ years; $\left.68.1 \pm 8.3 \mathrm{~kg} ; 1.51 \pm 0.06 \mathrm{~m} ; 29.8 \pm 3.9 \mathrm{~kg} / \mathrm{m}^{2}\right)$ and without MetS $(\mathrm{n}=81 ; 68.0 \pm 5.8$ years; $61.0 \pm 9.4 \mathrm{~kg} ; 1.53 \pm 0.06 \mathrm{~m}$; $26.0 \pm 3.9 \mathrm{~kg} / \mathrm{m}^{2}$ ). MetS was defined according to the criteria of the National Cholesterol Education Program's Adult Treatment Panel III: waist circumference $(\mathrm{WC})>88 \mathrm{~cm}$; triglycerides $\geq 150 \mathrm{mg} / \mathrm{dL}$; high-density lipoprotein cholesterol (HDL-C) $<50 \mathrm{mg} / \mathrm{dL}$; fasting glucose $\geq 110 \mathrm{mg} / \mathrm{dL}$; systolic blood pressure (SBP) $\geq 130 \mathrm{mmHg}$; or diastolic blood pressure $(\mathrm{DBP}) \geq 85 \mathrm{mmHg}$. The local Ethics Committee for Human Research approved the methods of the present study, and all participants signed an informed consent document.

\section{Anthropometric measures}

Anthropometric status was investigated by the following measures: height and body mass were measured for the calculation of the body mass index (BMI). All circumferences were obtained using a nonelastic tape; measurements were obtained in triplicate and then averaged. WC was measured at the midpoint between the lower rib margin and the iliac crest, hip circumference was measured around the widest portion of the hip. Percentage body fat and lean body mass were determined by dual-energy X-ray absorptiometry (General Electric-GE model 8548 BX1L, year 2005, Lunar DPX type, software Encore 2005; Rommelsdorf, Germany).

\section{Inflammatory parameters}

After an overnight fast, $3 \mathrm{~mL}$ blood samples were drawn from the antecubital vein in Vacutainer ${ }^{\circledR}$ tubes (Becton, Dickinson, and Company, Franklin Lakes, NJ, USA). These samples were centrifuged at $2500 \mathrm{rpm}$ at $4^{\circ} \mathrm{C}$ for 20 minutes. Samples were stored in aliquots in Eppendorf tubes (Eppendorf, Hamburg, Germany) at $-80^{\circ} \mathrm{C}$ until analysis. The inflammatory parameters measured were: CRP, interleukin-6 (IL-6), tumor necrosis factor- $\alpha$ (TNF- $\alpha$ ), and interferon- $\gamma($ INF- $\gamma)$. CRP was measured by the turbidimetric method with intensification by a particles reaction in the spectrophotometer Cobas Mira ${ }^{\circledR}$ Plus (Roche Diagnostics, Basel, Switzerland), using a calibrator and control serum of Biosystem (Bayer AG, Leverkusen, Germany). The intraassay coefficient of variation (CV) for CRP was 3.2\%-3.7\% 
and the interassay $\mathrm{CV}$ was $5.1 \%-6.3 \%$. Cytokines were measured by Quantikine ${ }^{\circledR}$ or Quantikine HS $^{\circledR}$ (high sensitivity) commercial enzyme-linked immunosorbent assay kits (R\&D Systems, Minneapolis, MN, USA). The intraassay CV of the kits was $2.1 \%-4.9 \%$ for IL-6, $2.2 \%-4.9 \%$ for INF- $\gamma$, and $2.3 \%-5.4 \%$ for TNF- $\alpha$. The interassay CV was $4.6 \%-6.6 \%$ for IL-6, 3.3\%-6.7\% for INF- $\gamma$, and 3.6\%-6.3\% for TNF- $\alpha$. The measures were performed in triplicate. To avoid any interference in the cytokine blood levels, subjects were asked to avoid exercise and using any type of substance with anti-inflammatory action at least 72 hours before the blood sample collection.

\section{Metabolic profile}

The lipid profile was determined by an enzymatic method (AutohumaLyzer (model 900S); HUMAN GmbH, Wiesbaden, Germany). Fasting glycemia was performed by ionic exchange technique with a colorimetric reaction. Glycosylated hemoglobin and basal insulinemia were measured by radioimmunoassay with kits from Merck Millipore (Billerica, MA, USA). The intra-assay CV of the kits was $2.3 \%-6.8 \%$ and $2.1 \%-6.2 \%$, respectively. The interassay CV was $6.9 \%-8.7 \%$ and $7.4 \%-9.1 \%$, respectively. Insulin and glucose values were used to calculate the homeostasis model assessment of insulin resistance (HOMA-IR) by using the following formula: HOMA-IR = fasting glucose $(\mathrm{mmol} / \mathrm{L}) \times$ fasting insulin $(\mu \mathrm{U} / \mathrm{mL}) / 22.5 .{ }^{13}$

\section{Blood pressure measurement}

SBP, DBP, and mean blood pressure (MBP) were measured with an oscillometric device (BP 3AC1-1 PC; Microlife AG, Widnau, Switzerland) according to the recommendations of the Brazilian Society of Cardiology. ${ }^{14}$ The cuff size was adapted to the circumference of the arm of each participant according to the manufacturer's recommendations. SBP and DBP values were used to determine MBP according to the following equation: $\mathrm{MBP}=\mathrm{DBP}+([\mathrm{SBP}-\mathrm{DBP}] / 3)$.

\section{MetS definition}

Women were classified with MetS according to the criteria of the National Cholesterol Education Program's Adult Treatment Panel III. Additionally, as previously described, ${ }^{15}$ the MetS Z-score used in the present study was defined by five MetS criteria. A modified Z-score was calculated for each variable using individual subject data following the Adult Treatment Panel III criteria. The equations used to calculate the MetS Z-score were as follows: Z-score $=([50-\mathrm{HDL}-\mathrm{C} \mathrm{mg} / \mathrm{dL}] / 11.8)+$
$([$ triglycerides $\mathrm{mg} / \mathrm{dL}-150] / 66.2)+([$ fasting blood glucose $\mathrm{mg} / \mathrm{dL}-110] / 10.4)+([\mathrm{WC} \mathrm{cm}-88] / 9.2)+([$ mean arterial pressure $\mathrm{mmHg}-100] / 8.7) / 100$.

\section{Statistical analysis}

The significance level for all variables studied was $P \leq 0.05$. Initially a descriptive analysis of the variables was carried out with central trend and dispersion data. Next, the Kolmogorov-Smirnov test and Levene's test were conducted to assess data normalcy and homoscedasticity, respectively. Individuals were separated as having or not having MetS. Differences between groups for anthropometric data, blood pressure, biochemical, and inflammatory parameters were evaluated by unpaired Student's $t$-test and Mann-Whitney signed-rank test for nonparametric data. In addition, the correlation between MetS Z-score and anthropometric data, blood pressure, biochemical, and inflammatory parameters was evaluated by the correlation of Pearson's chi-squared test and Spearman's rank correlation coefficient. One-way analysis of variance with the Bonferroni post hoc test and Kruskal-Wallis test was used to compare groups separated by an optimal risk group (zero or one component) with those presenting two to three combined and four to five combined MetS components. Data were analyzed using SPSS ${ }^{\circledR}$ version 19 (IBM Corporation, Armonk, NY, USA).

\section{Results}

The anthropometric, biochemical, inflammatory, and blood pressure parameters of the groups of older women with and without MetS are presented in Table 1. There was no difference between the groups regarding age $(P=0.12)$, height $(P=0.19)$, fat mass $(P=0.09)$, glycosylated hemoglobin $(P=0.28)$, total cholesterol $(P=0.82)$, and low-density lipoprotein cholesterol $(P=0.16)$. However, as expected, older women with MetS presented higher body mass $(P=0.002)$, BMI $(P=0.001)$, WC $(P=0.001)$, hip circumference $(P=0.04)$, waist-hip ratio $(P=0.001)$, waist-height ratio $(P=0.001)$, SBP $(P=0.001)$, DBP $(P=0.001), \operatorname{MBP}(P=0.001)$, glucose $(P=0.001)$, insulin $(P=0.001)$, HOMA-IR $(P=0.001)$, MetS Z-score $(P=0.001)$, and lower lean body mass $(P=0.03)$ values when compared with women without MetS. Table 2 presents the anthropometric, biochemical, and blood pressure parameters of the older women considering each of the individual MetS components. Individuals presenting more than two components exhibited worse anthropometric, biochemical, and blood pressure status, while TNF- $\alpha$ was higher in women with more than two components as compared with those with zero or one component (Figure 1). 
Table I Subjects' characteristics

\begin{tabular}{|c|c|c|c|}
\hline & $\begin{array}{l}\text { MetS } \\
(n=48)\end{array}$ & $\begin{array}{l}\text { Without MetS } \\
(n=8 \mathrm{I})\end{array}$ & $P(95 \% \mathrm{Cl})$ \\
\hline Age (years) & $66.4 \pm 4.1$ & $67.9 \pm 5.8$ & $0.12(-0.41,3.45)$ \\
\hline Weight (kg) & $69.9 \pm 7.4$ & $65.4 \pm 7.4^{*}$ & $0.002(-7.27,-1.68)$ \\
\hline Height (m) & $\mid .51 \pm 0.1$ & $1.53 \pm 0.1$ & $0.19(-0.001,0.03)$ \\
\hline BMI $\left(\mathrm{kg} / \mathrm{m}^{2}\right)$ & $30.5 \pm 3.4$ & $28.0 \pm 2.9^{*}$ & $0.001(-3.68,-1.36)$ \\
\hline WC $(\mathrm{cm})$ & $98.2 \pm 7.9$ & $90.3 \pm 8.1^{*}$ & $\mathbf{0 . 0 0 I}(-10.9,-4.85)$ \\
\hline $\mathrm{HC}(\mathrm{cm})$ & $105.2 \pm 6.4$ & $102.8 \pm 6.5^{*}$ & $\mathbf{0 . 0 4}(-4.86,-0.0 \mathrm{I})$ \\
\hline Waist-hip ratio & $0.93 \pm 0.01$ & $0.88 \pm 0.07^{*}$ & $\mathbf{0 . 0 0 I}(-0.8 \mathrm{I},-0.28)$ \\
\hline Waist-height ratio & $0.65 \pm 0.05$ & $0.59 \pm 0.06 *$ & $\mathbf{0 . 0 0 I}(-0.07,-0.35)$ \\
\hline LBM (\%) & $54.9 \pm 3.1$ & $56.28 \pm 3.5^{*}$ & $0.03(0.08,2.59)$ \\
\hline FM (\%) & $4 I .7 \pm 3.3$ & $40.56 \pm 3.9$ & $0.09(-2.56,0.19)$ \\
\hline $\mathrm{SBP}(\mathrm{mmHg})$ & $151.8 \pm 21.8$ & $128.73 \pm 25.4^{*}$ & $0.001(-32.1,-14.1)$ \\
\hline $\mathrm{DBP}(\mathrm{mmHg})$ & $91.8 \pm 11.3$ & $77.8 \pm 13.7^{*}$ & $0.001(-18.8,-9.3)$ \\
\hline $\mathrm{MBP}(\mathrm{mmHg})$ & $111.8 \pm 13.4$ & $94.8 \pm 16.8^{*}$ & $0.001(-22.8,-11.2)$ \\
\hline Glucose (mg/dL) & $116.9 \pm 42.3$ & $94.0 \pm 12.4 *$ & $0.001(-34.3,-12.0)$ \\
\hline $\mathrm{HbA}_{\mathrm{Ic}}(\%)$ & $5.69 \pm 0.8$ & $5.55 \pm 0.5$ & $0.28(-0.39,0.11)$ \\
\hline Insulin $(\mu \mathrm{U} / \mathrm{mL})^{\dagger}$ & $14.5 \pm 9.1$ & $9.4 \pm 4.5$ & 0.001 \\
\hline $\mathrm{HOMA}^{\prime} \mathrm{R}^{\dagger}$ & $4.6 \pm 5.2$ & $2.2 \pm 1.1$ & 0.001 \\
\hline Total cholesterol (mg/dL) & $237.2 \pm 40.3$ & $239 \pm 41.5$ & $0.82(-13.7,17.1)$ \\
\hline Triglycerides (mg/dL) & $213.4 \pm 76.2$ & $120.4 \pm 44.1$ & $0.00 I(-1 \mid 5.6,-70.2)$ \\
\hline HDL-C (mg/dL) & $55.9 \pm 11.6$ & $63 \pm 10.1$ & $0.001(2.83,-10.9)$ \\
\hline MetS Z-score & $1.48 \pm 0.13$ & $1.26 \pm 0.17^{*}$ & $\mathbf{0 . 0 0 I}(-0.27,-0.16)$ \\
\hline
\end{tabular}

Note: Bold indicates a significant difference $(P \leq 0.05)$. ${ }^{\dagger}$ Values expressed as median.

Abbreviations: BMI, body mass index; $\mathrm{Cl}$, confidence interval; DBP, diastolic blood pressure; FM, fat mass; $\mathrm{HbA}_{\mathrm{Ic}}$, hemoglobin $\mathrm{A}_{\mathrm{Ic}}$ (glycosylated hemoglobin); HC, hip circumference; HDL-C, high-density lipoprotein cholesterol; HOMA-IR, homeostasis model assessment of insulin resistance; LBM, lean body mass; MBP, mean blood pressure; MetS, metabolic syndrome; SBP, systolic blood pressure; WC, waist circumference.

The inflammatory markers levels are shown in Figure 2. Women with MetS had significantly higher levels of TNF- $\alpha(P=0.04)$ and INF- $\gamma(P=0.03)$ compared with women without MetS, while IL-6 and CRP levels were not significantly different between groups.

The correlation among the variables of the study is summarized in Table 3. There were correlations of MetS Z-score with body mass ( $\mathrm{r}=0.20 ; P=0.03), \mathrm{WC}(\mathrm{r}=0.26$; $P=0.005)$, waist-hip ratio $(\mathrm{r}=0.32 ; P=0.001)$, waist-height ratio $(\mathrm{r}=0.24 ; P=0.01)$, blood glucose $(\mathrm{r}=0.24 ; P=0.01)$, insulin ( $\mathrm{r}=0.24 ; P=0.01)$, HOMA-IR $(\mathrm{r}=0.32 ; P=0.001)$, triglycerides $(\mathrm{r}=0.39 ; P=0.001)$, and an inverse correlation with HDL-C $(\mathrm{r}=-0.32 ; P=0.005)$. In addition, MetS Z-score was highly associated with SBP $(\mathrm{r}=0.92 ; P=0.0001)$, DBP $(\mathrm{r}=0.94 ; P=0.0001)$, and $\mathrm{MBP}(\mathrm{r}=0.98 ; P=0.0001)$ (Figure 3).

\section{Discussion}

In the current study, the cytokine levels of older women with and without MetS were compared. Additionally, the correlations between inflammatory parameters, anthropometric measures, metabolic profile, and blood pressure with MetS Z-score were investigated. Confirming the initial hypothesis, women with MetS presented higher blood inflammatory markers (TNF- $\alpha$ and INF- $\gamma$ ), anthropometric, biochemical, and blood pressure parameters when compared with the older women without MetS. Moreover, elderly women with at least two components of MetS presented higher TNF- $\alpha$, anthropometric, biochemical, and blood pressure parameters when compared with the older women with less than two components of MetS. Furthermore, MetS Z-score was associated with anthropometric measures (weight, WC, waist-hip ratio, and waist-height ratio), metabolic profile (glucose, insulin, HOMA-IR, triglycerides, and HDL-C), cytokines, and blood pressure (SBP, DBP, and MBP).

Banks et al found that TNF- $\alpha$ was more elevated in elderly individuals with insulin resistance as compared with elderly without insulin resistance. ${ }^{16}$ They stated that the lack of correlation between TNF- $\alpha$ and BMI or leptin suggests that this cytokine did not originate from fat. Interestingly, the current results revealed that although there was no difference in fat mass between elderly women with and without MetS, the greater the number of components of MetS, the more elevated TNF- $\alpha$. Possibly, this cytokine is not coming from the adipose tissue. 
Table 2 Characteristics of subjects according to the components of metabolic syndrome

\begin{tabular}{|c|c|c|c|}
\hline & $\begin{array}{l}0-1 \text { component } \\
(n=39)\end{array}$ & $\begin{array}{l}2-3 \text { components } \\
(n=73)\end{array}$ & $\begin{array}{l}\text { 4-5 components } \\
(n=18)\end{array}$ \\
\hline Age (years) & $67.9 \pm 5.9$ & $67.2 \pm 5.4$ & $66.8 \pm 4.2$ \\
\hline Weight (kg) & $56.9 \pm 8.7$ & $65.7 \pm 8.7^{*}$ & $70.3 \pm 6.5^{*}$ \\
\hline Height (m) & $1.53 \pm 0.07$ & $1.52 \pm 0.06$ & $1.51 \pm 0.06$ \\
\hline BMI $\left(\mathrm{kg} / \mathrm{m}^{2}\right)$ & $24.3 \pm 3.6$ & $28.4 \pm 3.7^{*}$ & $30.9 \pm 3.9$ \\
\hline WC (cm) & $81.3 \pm 10.1$ & $93.5 \pm 8.7^{*}$ & $98.8 \pm 4.5^{*, *}$ \\
\hline $\mathrm{HC}(\mathrm{cm})$ & $96.1 \pm 7.0$ & $101.7 \pm 7.7^{*}$ & $104.7 \pm 4.9^{*}$ \\
\hline Waist-hip ratio & $0.84 \pm 0.07$ & $0.92 \pm 0.07 *$ & $0.95 \pm 0.05$ \\
\hline Waist-height ratio & $0.53 \pm 0.07$ & $0.62 \pm 0.06^{*}$ & $0.65 \pm 0.04^{* * *}$ \\
\hline LBM (\%) & $63.3 \pm 7.5$ & $57.8 \pm 5.0^{*}$ & $55.4 \pm 3.6^{*}$ \\
\hline FM (\%) & $32.6 \pm 7.8$ & $38.7 \pm 5.4^{*}$ & $41.4 \pm 3.8^{*}$ \\
\hline $\mathrm{SBP}(\mathrm{mmHg})$ & $124.3 \pm 18.8$ & $147.5 \pm 25.2^{*}$ & $|56.| \pm 21.2^{*}$ \\
\hline $\mathrm{DBP}(\mathrm{mmHg})$ & $75.9 \pm 12.1$ & $87.4 \pm 13.3^{*}$ & $94.4 \pm 10.9 *$ \\
\hline $\mathrm{MBP}(\mathrm{mmHg})$ & $92.0 \pm 13.3$ & $107.4 \pm 16.1^{*}$ & $115.0 \pm 13.0 *$ \\
\hline Glucose (mg/dL) & $89.8 \pm 12.3$ & $102.5 \pm 25.9 *$ & $132.5 \pm 49.7^{*, *}$ \\
\hline $\mathrm{HbA}_{\mathrm{Ic}}(\%)$ & $5.5 \pm 0.6$ & $5.6 \pm 0.7$ & $5.7 \pm 1.1$ \\
\hline Insulin $(\mu \mathrm{U} / \mathrm{mL})^{\dagger}$ & $5.8 \pm 6.8$ & $9.5 \pm 6.7$ & $18.3 \pm 10.9$ \\
\hline HOMA-IR ${ }^{\dagger}$ & $\mathrm{I} .7 \pm \mathrm{I} . \mathrm{I}$ & $2.3 \pm 3.2$ & $4.8 \pm 5.9$ \\
\hline Total cholesterol (mg/dL) & $225.9 \pm 31.0$ & $238.7 \pm 43.8$ & $246.9 \pm 31.9$ \\
\hline Triglycerides (mg/dL) & $100.8 \pm 43.4$ & $165.3 \pm 58.6$ & $239.6 \pm 74.2^{*, *}$ \\
\hline HDL-C (mg/dL) & $63.5 \pm 7.9$ & $61.2 \pm 11.3$ & $50.3 \pm 9.0^{*, *}$ \\
\hline MetS Z-score & $1.22 \pm 0.13$ & $1.41 \pm 0.16^{*}$ & $1.54 \pm 0.1 I^{* * *}$ \\
\hline
\end{tabular}

Notes: *Different from zero or one component $(P \leq 0.05) ;{ }^{*}$ different from two or three components $(P \leq 0.05)$. ${ }^{\dagger} V$ alues expressed as median.

Abbreviations: BMI, body mass index; DBP, diastolic blood pressure; FM, fat mass; $\mathrm{HbA}_{\mathrm{Ic}}$, hemoglobin $\mathrm{A}_{\mathrm{lc}}$ (glycosylated hemoglobin); $\mathrm{HC}$, hip circumference; HDL-C, highdensity lipoprotein cholesterol; HOMA-IR, homeostasis model assessment of insulin resistance; LBM, lean body mass; MBP, mean blood pressure; MetS, metabolic syndrome; SBP, systolic blood pressure; WC, waist circumference.

Adiponectin has been proposed as a significant genetic contributor to MetS phenotype in older persons. ${ }^{17}$ It has been found that among 1438 subjects aged 65-88 years, the single nucleotide polymorphism 276 in intron- 2 was associated with the risk of obesity and MetS independent of age and sex (GG genotype presenting lower risk). It was also associated to the risk of diabetes with an additive mode of inheritance, independent of age, sex, and BMI. ${ }^{17}$

The Framingham Offspring Study, which included 2406 men and 2569 women aged 19-74 years, examined

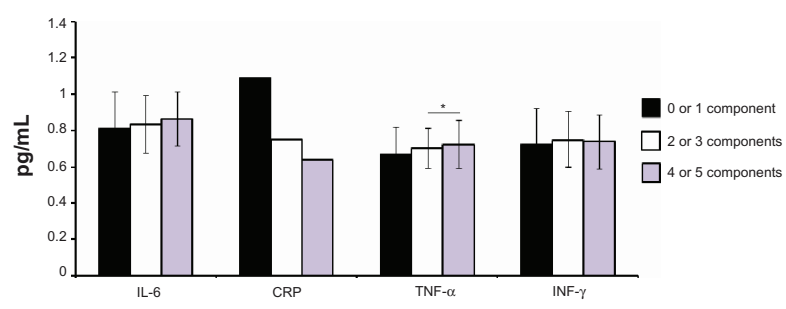

Figure I Inflammatory parameters in elderly women according to the presence of different components of metabolic syndrome.

Notes: *Significantly different from zero or one component $(P \leq 0.05)$; CRP data is presented as median.

Abbreviations: CRP, C-reactive protein; IL-6, interleukin-6; INF- $\gamma$, interferon- $\gamma$; TNF- $\alpha$, tumor necrosis factor- $\alpha$. the clustering of metabolic factors in relation to coronary heart disease risk. ${ }^{18}$ The six metabolically linked risk factors considered were HDL-C level (the lowest sexspecific quintile), BMI, SBP, triglycerides, glucose, and total cholesterol levels (the highest quintiles). With a cluster of three or more risk factors, the risk of coronary heart disease increased 2.4-fold for men and 5.9-fold for women. These results are in accordance with Cabrera et al, who demonstrated that the risk of cardiovascular events was statistically significant for the following variables: diabetes

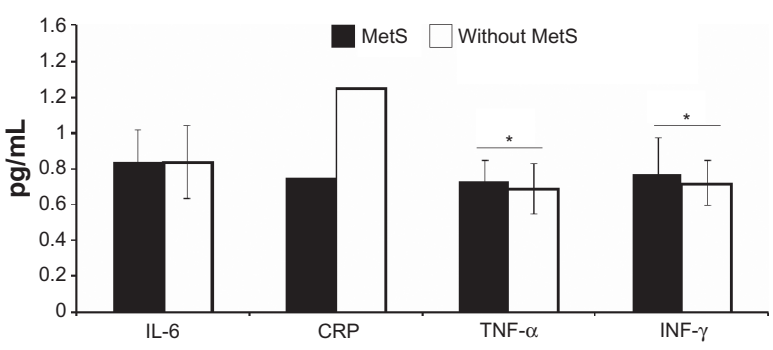

Figure 2 Inflammatory parameters in elderly women with and without MetS. Notes: *Significant difference between groups $(P \leq 0.05)$; CRP data is presented as median.

Abbreviations: CRP, C-reactive protein; IL-6, interleukin-6; INF- $\gamma$, interferon- $\gamma$; MetS, metabolic syndrome; TNF- $\alpha$, tumor necrosis factor- $\alpha$. 
Table 3 Correlation coefficient of metabolic syndrome Z-score (dependent variable) and anthropometric measures, metabolic profile, and inflammatory parameters

\begin{tabular}{|c|c|c|}
\hline Independent variables & Correlation & $P$ \\
\hline \multicolumn{3}{|l|}{ Anthropometric measures } \\
\hline Weight (kg) & $0.20 *$ & 0.03 \\
\hline BMI & 0.18 & 0.06 \\
\hline$W C(\mathrm{~cm})$ & $0.26 *$ & 0.005 \\
\hline $\mathrm{HC}(\mathrm{cm})$ & -0.03 & 0.75 \\
\hline Waist-hip ratio & $0.32 *$ & 0.001 \\
\hline Waist-height ratio & $0.24 *$ & 0.01 \\
\hline LBM (\%) & -0.02 & 0.79 \\
\hline FM (\%) & -0.03 & 0.76 \\
\hline \multicolumn{3}{|l|}{ Metabolic profile } \\
\hline Glucose (mg/dL) & $0.24 *$ & 0.01 \\
\hline $\mathrm{HbA}_{\mathrm{Ic}}(\%)$ & 0.06 & 0.53 \\
\hline Insulin $(\mu \mathrm{U} / \mathrm{mL})^{\dagger}$ & $0.24 *$ & 0.01 \\
\hline HOMA-IR $^{\dagger}$ & $0.32 *$ & 0.001 \\
\hline Total cholesterol (mg/dL) & 0.02 & 0.78 \\
\hline Triglyceride (mg/dL) & $0.39 *$ & 0.001 \\
\hline $\mathrm{HDL}-\mathrm{C}(\mathrm{mg} / \mathrm{dL})$ & $-0.26 *$ & 0.005 \\
\hline \multicolumn{3}{|l|}{ Inflammatory parameters } \\
\hline IL-6 & 0.09 & 0.28 \\
\hline CRP & -0.03 & 0.72 \\
\hline TNF- $\alpha$ & $0.28 *$ & 0.002 \\
\hline INF- $\gamma$ & $0.22 *$ & 0.01 \\
\hline
\end{tabular}

Note: Bold indicates a significant correlation $(P \leq 0.05)$. ${ }^{\dagger}$ Values expressed as median. Abbreviations: $\mathrm{BMI}$, body mass index; CRP, C-reactive protein; FM, fat mass; $\mathrm{HbA}_{\mathrm{Ic}}$, hemoglobin $\mathrm{A}_{\mathrm{Ic}}$ (glycosylated hemoglobin); $\mathrm{HC}$, hip circumference; HDL-C, high-density lipoprotein cholesterol; HOMA-IR, homeostasis model assessment of insulin resistance; IL-6, interleukin-6; INF- $\gamma$, interferon- $\gamma$; LBM, lean body mass; TNF- $\alpha$, tumor necrosis factor- $\alpha$; WC, waist circumference.

(hazard ratio [HR] 2.67; 95\% confidence interval [CI] $1.98-3.61 ; P=0.001$ ), prediabetes or diabetes (HR 1.60; 95\% CI 1.23-2.08; $P=0.001$ ), hypertension (HR 1.69; 95\% CI $1.28-2.24 ; P=0.001$ ), MetS (HR 1.61; 95\% CI 1.24-2.09; $P=0.001$ ), increased waist-hip ratio (HR 1.36; 95\%
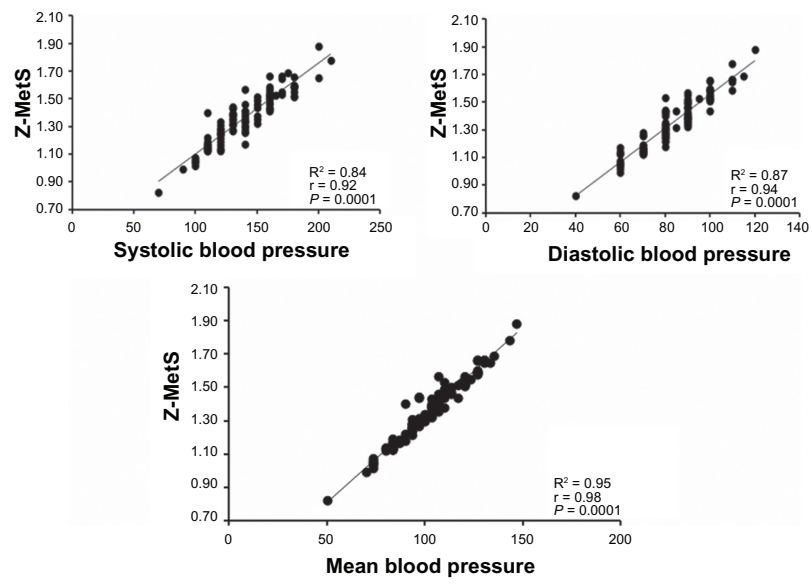

Figure 3 Correlation coefficient of Z-MetS with blood pressure. Abbreviation: Z-MetS, metabolic syndrome Z-score.
CI 1.03-1.79; $P=0.05$ ), hypertriglyceridemia (HR 1.67; 95\% CI 1.22-2.30; $P=0.01$ ), and high triglyceride/HDL-C ratio (HR $1.73 ; 95 \%$ CI $1.31-2.84 ; P=0.001) .{ }^{19}$ In this sense, the current results revealed that women with MetS presented higher cardiovascular risk factors. Therefore, preventive measures and early detection of targets are needed. Furthermore, a higher number of accumulated risk factors will produce additional inflammatory and metabolic disturbances in elderly women.

Despite the high prevalence of MetS and the intense interest in this syndrome during much of this decade, recognition by the public appears limited. A survey with 211,097 adults found that only $0.6 \%$ knew they had MetS and $<15 \%$ cognized the existence of MetS. ${ }^{20}$ The low percentage of respondents in that survey who reported having ever been told that they had MetS calls into question how unsuccessful health care providers are in diagnosing MetS. To date, the current findings contribute to literature and highlight the association between inflammatory parameters, anthropometric measures, metabolic profile, and blood pressure with MetS Z-score in elderly women. More specifically, results of blood pressure are of great interest and have optimal clinical application, as blood pressure was strongly correlated with MetS Z-score.

In the present study, cytokines were significantly higher in elderly women with MetS and in those presenting at least two components of MetS when compared with elderly women without MetS or less than two components of MetS, respectively. Similarly, Chen et al revealed that subjects suffering from MetS may have a higher inflammation status (CRP, IL-6) and a higher level of oxidative stress. ${ }^{21}$ Moreover, a higher inflammation status was significantly correlated with an increase in the risk of MetS. Similarly, Ingelsson et al reported that a higher inflammation status (evaluated by vascular cell adhesion molecule-1, E-selectin, and CRP) were independently associated with MetS. ${ }^{22}$ These biomarkers were also independently associated with HOMA-IR. These data reinforce the importance of including blood markers of inflammation to improve the diagnosis of MetS in elderly individuals.

There are some limitations in the current study. Due to the reduced number of participants and the cross-sectional design, no causal relationship could be defined. Larger, prospective studies are needed to establish the relationship between inflammation and MetS. In addition, only CRP, IL-6, TNF- $\alpha$, and INF- $\gamma$ were selected as inflammatory markers; further studies could select more sensitive markers of inflammation in subjects with MetS. 


\section{Conclusion}

Subjects suffering from MetS have higher cytokine levels and cardiovascular risk factors. Although the correlations were weak, higher cytokine levels were significantly correlated with MetS Z-score. Furthermore, older women with higher blood pressure are more strongly correlated with MetS Z-score. The inclusion of blood biomarkers of inflammation, such as cytokines and CRP, is proposed to improve the diagnosis and the determination of severity status for MetS in elderly individuals.

\section{Disclosure}

The authors report no conflicts of interest in this work.

\section{References}

1. Eckel RH, Grundy SM, Zimmet PZ. The metabolic syndrome. Lancet 2005;365(9468):1415-1428.

2. Cornier MA, Dabelea D, Hernandez TL, et al. The metabolic syndrome. Endocr Rev. 2008;29(7):777-822.

3. Ford ES, Giles WH. A comparison of the prevalence of the metabolic syndrome using two proposed definitions. Diabetes Care. 2003;26(3): 575-581.

4. Park YW, Zhu S, Palaniappan L, Heshka S, Carnethon MR, Heymsfield SB. The metabolic syndrome: prevalence and associated risk factor findings in the US population from the Third National Health and Nutrition Examination Survey, 1988-1994. Arch Intern Med. 2003;163(4):427-436.

5. Kolovou GD, Anagnostopoulou KK, Salpea KD, Mikhailidis DP. The prevalence of metabolic syndrome in various populations. Am J Med Sci. 2007;333(6):362-371.

6. Dutra ES, de Carvalho KM, Miyazaki E, Hamann EM, Ito MK. Metabolic syndrome in central Brazil: prevalence and correlates in the adult population. Diabetol Metab Syndr. 2012;4(1):20.

7. Hotamisligil GS. Inflammation and metabolic disorders. Nature. 2006; 444(7121):860-867.

8. Pischon T, Hu FB, Rexrode KM, Girman CJ, Manson JE, Rimm EB Inflammation, the metabolic syndrome, and risk of coronary heart disease in women and men. Atherosclerosis. 2008;197(1):392-399.
9. Haffner SM. The metabolic syndrome: inflammation, diabetes mellitus, and cardiovascular disease. Am J Cardiol. 2006;97(2A):3A-11A.

10. Lumeng CN, Saltiel AR. Inflammatory links between obesity and metabolic disease. J Clin Invest. 2011;121(6):2111-2117.

11. Han TS, Sattar N, Williams K, Gonzalez-Villalpando C, Lean ME, Haffner SM. Prospective study of C-reactive protein in relation to the development of diabetes and metabolic syndrome in the Mexico City Diabetes Study. Diabetes Care. 2002;25(11):2016-2021.

12. Prestes J, Shiguemoto G, Botero JP, et al. Effects of resistance training on resistin, leptin, cytokines, and muscle force in elderly post-menopausal women. J Sports Sci. 2009;27(14):1607-1615.

13. Katsuki A, Sumida Y, Gabazza EC, et al. Homeostasis model assessment is a reliable indicator of insulin resistance during follow-up of patients with type 2 diabetes. Diabetes Care. 2001;24(2):362-365.

14. Sociedade Brasileira de Cardiologia. VI diretriz Brasileira de hipertensao [VI Brazilian guidelines on hypertension]. Arq Bras Cardiol. 2010;95(Suppl 1):1-51. Portuguese.

15. Johnson JL, Slentz CA, Houmard JA, et al. Exercise training amount and intensity effects on metabolic syndrome (from Studies of a Targeted Risk Reduction Intervention Through Defined Exercise). Am J Cardiol. 2007;100(12):1759-1766

16. Banks WA, Willoughby LM, Thomas DR, Morley JE. Insulin resistance syndrome in the elderly: assessment of functional, biochemical, metabolic, and inflammatory status. Diabetes Care. 2007;30(9):2369-2373.

17. Yang WS, Yang YC, Chen CL, et al. Adiponectin SNP276 is associated with obesity, the metabolic syndrome, and diabetes in the elderly. Am J Clin Nutr. 2007;86(2):509-513.

18. Wilson PW, Kannel WB, Silbershatz H, D'Agostino RB. Clustering of metabolic factors and coronary heart disease. Arch Intern Med. 1999;159(10):1104-1109.

19. Cabrera MA, de Andrade SM, Mesas AE. A prospective study of risk factors for cardiovascular events among the elderly. Clin Interv Aging. 2012;7:463-468.

20. Lewis SJ, Rodbard HW, Fox KM, Grandy S. Self-reported prevalence and awareness of metabolic syndrome: findings from SHIELD. Int $J$ Clin Pract. 2008;62(8):1168-1176.

21. Chen SJ, Yen CH, Huang YC, Lee BJ, Hsia S, Lin PT. Relationships between inflammation, adiponectin, and oxidative stress in metabolic syndrome. PLoS One. 2012;7(9):e45693.

22. Ingelsson $\mathrm{E}$, Hulthe $\mathrm{J}$, Lind $\mathrm{L}$. Inflammatory markers in relation to insulin resistance and the metabolic syndrome. Eur $J$ Clin Invest. 2008;38(7):502-509.
Clinical Interventions in Aging

\section{Publish your work in this journal}

Clinical Interventions in Aging is an international, peer-reviewed journal focusing on evidence-based reports on the value or lack thereof of treatments intended to prevent or delay the onset of maladaptive correlates of aging in human beings. This journal is indexed on PubMed Central, MedLine, the American Chemical Society's 'Chemical Abstracts

\section{Dovepress}

Service' (CAS), Scopus and the Elsevier Bibliographic databases. The manuscript management system is completely online and includes a very quick and fair peer-review system, which is all easy to use. Visit http://www.dovepress.com/testimonials.php to read real quotes from published authors. 